\title{
Mantua y otras posibles cabeceras de ciudades romanas en el ámbito de la Comunidad de Madrid
}

\author{
Julio Mangas MANJARRÉS \\ Universidad Complutense de Madrid \\ jmangas@ghis.ucm.es \\ Sandra AzCÁRraga CÁMARA \\ Museo Arqueológico Regional de la Comunidad de Madrid \\ sandra.azcarraga@gmail.com \\ Gabriela MäRTEnS Alfaro \\ Museo Arqueológico Regional de la Comunidad de Madrid \\ gabriela.martens@madrid.org
}

\section{RESUMEN}

El presente artículo tiene como objetivo revisar la documentación literaria, arqueológica y epigráfica referente a las ciudades romanas que se crearon en la actual demarcación de la Comunidad de Madrid. Se argumenta a favor de la localización de Mantua en la actual Villamanta y de la existencia de otras cabeceras de civitates en las ruinas de La Dehesa de la Oliva (Patones) y en, o cerca de, Collado Villaba o de San Lorenzo de El Escorial.

Palabras clave: Civitas. Vicus. Mantua. Carpetania. Romanización.

\section{Mantua and Other Likely Roman Towns in the Comunidad de Madrid}

\begin{abstract}
This paper aims to revise the literary, epigraphical and archaeological evidence in order to identify the Roman towns in the current Comunidad de Madrid. It argues that Mantua was located in current Villamanta and that other civitatum capita might have been in La Dehesa de la Oliva (Patones), Collado Villalba or San Lorenzo de El Escorial.
\end{abstract}

Key Words: Civitas. Vicus. Mantua. Carpetania. Romanization.

Sumario: 1. Mantua. 2. Madrid: ¿cabecera de una civitas o de un vicus?. 3. Cabecera en el nordeste de la Comunidad de Madrid. 4. Cabecera de civitas en el noroeste de la Comunidad de Madrid. 5. Conclusiones 
Resulta bien conocido que el ámbito territorial de la actual Comunidad de Madrid formaba parte del territorio más extenso de la antigua Carpetania. Ahora bien, en los relatos de los acontecimientos bélicos relacionados con la conquista romana de la Carpetania así como en otros relatos posteriores del período de las guerras civiles romanas, surgen nombres de ciudades carpetanas que se encuentran en el territorio de las actuales provincias de Toledo (Toletum, Consabura y Lebura / Albura) y de Guadalajara (Segontia y Cáraca), ${ }^{1}$ pero no hay alusión alguna a núcleos urbanos del ámbito de la Comunidad de Madrid.

Las referencias de Plinio -es bien sabido que toma la información de comienzos del Imperio, de la obra de Agripa- incluyen la mención aislada del nombre de las ciudades más importantes, ante todo de aquellas que habían adquirido el rango de colonias romanas, de municipios romanos, de municipios latinos y de unas de las pocas ciudades libres o federadas, quedando las demás en el marco de la mención global de su número como estipendiarias, de dediticii, situación en la que se encontraban las ciudades del actual ámbito de la Comunidad de Madrid en los comienzos del Imperio. ${ }^{2}$

A pesar de la abundante y útil información de Plinio sobre el conjunto de Hispania, sus alusiones a la Carpetania son muy escasas; se limita a referirse a los Consaburenses y a los Toletani, como ciudades estipendiarias del conventus Carthaginiensis (Plin., nat. III 25), al Tajo (Plin., nat. IV 115), "célebre por sus arenas auríferas" -idea repetida en Estrabón (III 2.3), en Apiano (Iber. 63) y en otros autores-, a que "el comino más aceptado dentro de nuestro orbe es el de Carpetania" (Plin., nat. XIX 161) y a la excelente sal que se obtenía en bloques en la ciudad de Egelesta (Plin., nat. XXI 80 ), mencionada también por Ptolomeo como ciudad carpetana, aunque hay muchas dudas sobre su localización. El geógrafo Estrabón añade la referencia a la abundancia de peces y moluscos del Tajo (Str., III 3.19) así como a la existencia de montes metalíferos que bordean tanto el Tajo como el Guadiana -los Montes de Toledo- lo que contribuía a la esterilidad de las tierras vecinas (Str., III 2.3). Ahora bien, esas escasas noticias exigen siempre precisiones. Baste el siguiente ejemplo: mientras que Apiano (Iber. 6.64; 70) resalta la fertilidad de la tierra y la riqueza en vides y olivos, Estrabón alude a la "mediana fertilidad" al referirse a las zonas altas del Tajo y a las que se encuentran próximas a las zonas mineras (Str., III 1.6). Teniendo en cuenta los bajos niveles demográficos de esas épocas -se viene aceptando el cálculo de los 6-7 millones de personas para toda la Península-, nunca hubo dificultades para una cómoda subsistencia de los carpetanos; más aún, varios enclaves carpetanos sirvieron de centros de residencia y de subsistencia para las tropas romanas durante los años de la conquista de la Celtiberia, según relata Apiano (Iber. 83). A los geógrafos e historiadores greco-romanos, les interesó resaltar lo más sobresaliente, la existencia de productos que fueran útiles para la exportación -productos mineros, sal, comino, aceite y vino-; también, los cuchillos de Toletum, ya famosos en el s. I d.C., según el poeta Gattio (Cynegetica V 341).

1 Mangas, 2014.

2 Plin., nat. III 7; III 18; IV 117. Una revisión reciente en CASTILlo 2008, 31 ss. 
La organización romana del territorio conquistado en civitates se inició ya en época republicana ${ }^{3}$ y se completó entre fines de la República y comienzos del Imperio, aunque, en algún ámbito -sobre todo en el del asentamiento de tropas legionarias- se hicieron reajustes en épocas posteriores. ${ }^{4}$ Por lo mismo, el número y los nombres de las civitates en época de Augusto era igual o semejante al que nos da Ptolomeo a mediados del s. II d.C., quien enumera por su nombre cada una de las civitates / póleis carpetanas con la precisión de los grados de latitud y de longitud para una localización precisa. No entramos ahora en la compleja discusión sobre el valor del grado ptolemaico y en la consideración sobre el meridiano y el paralelo del que se sirvió para asignar los grados. Baste decir que nos consta que los copistas de su obra cometieron algunos errores y que, por lo mismo, la atención a las mediciones propuestas no sirve siempre para localizar con garantía las cabeceras de las civitates / póleis que enumera. ${ }^{5}$ Según Ptolomeo (II 6.56), el territorio de los carpetanos se distribuía entre las siguientes póleis / civitates: Ilurbida, Egelesta, Ilarcurís, Térmida, Titulcia, Mantua, Toleton, Cómpluton, Cáracca, Libora, Íspinon, Metércosa, Barnacis, Alternia, Paterniana, Rígusa, Laminion.

Hay que resaltar que Ptolomeo se equivocó al incluir Condabora / Consabura (Consuegra), ciudad carpetana, entre las ciudades celtíberas. También hay otro error en su referencia a Laminion (Alhambra, Ciudad Real), que no es ciudad carpetana, sino oretana. ${ }^{6}$ A su vez, tampoco menciona Segontia (Sigüenza, Guadalajara), que era también carpetana. Tales errores abren la posibilidad de que hubiera cometido otros.

Si tenemos presente la localización segura de Toleton (Toledo), Condabura / Consabura (Consuegra) y Libora (entre Toledo y Talavera de la Reina) ${ }^{7}$ así como la de Segontia (Sigüenza), nos quedan dos claramente localizadas en el ámbito de la Comunidad de Madrid: Complutum y Titulcia. Quedan, pues, por localizar las cabeceras de las siguientes civitates / póleis del ámbito de los carpetanos: Ilurbida, Egelesta, Ilarcurís, Térmida, Mantua, Cáracca, Íspinon, Metercosa, Barnacis, Alternia, Paterniana y Rígusa. Aún suponiendo que Ptolomeo hubiera cometido también otro error y alguna de éstas no fuera carpetana, quedan varias por localizar. Ahora bien, basta leer el estudio de García Alonso, donde se recogen las opiniones de muchos autores y sus propuestas, para comprobar que faltan muchas cabeceras de póleis / civitates por localizar: ${ }^{8}$

a) Esa larga lista se reduce si aceptamos alguna de las propuestas sobre la localización de Cáracca. El Anónimo de Rávena (IV 44), tras enumerar varias mansiones de las vías romanas, menciona, en relación con el occidente de Complutum, a Complutum - Titulciam - Toleton..., e indica en la otra dirección a las siguientes: ad aliam partem

\footnotetext{
3 López BarJa de Quiroga 2008, 9-11 y passim.

4 Ya se indicó en otro momento al referirse al ámbito de las provincias de León - Zamora: cf. MANGAS 2008, 85 ss, 96-99.

5 Una discusión detallada en Montero Vítores 1991.

6 Moya-Maleno 2008, 557 ss; CARRasco 2007: 27-29.

7 Sobre Libora / Lebura / Albora / Albura, situada entre Toledo y Talavera de la Reina, cf. Mangas 2014.

8 GARCía Alonso 2007, 71-92, donde va enumerando todas las cabeceras de civitates / póleis y las varias e inseguras propuestas sobre su localización.
} 
iuxta ipsam civitatem Complito dicitur civitas id est Pirascon - Albeceia - CaucaNibaria - Abulobriga - Intercatia - Palentia. Ninguna de éstas últimas, salvo Complutum / Complito, coincide con las póleis mencionadas por Ptolomeo para la Carpetania. Ahora bien, en otro pasaje del Ravenate (IV 44), se indica: iuxta ipsam civitatem Complutum est civitas quae dicitur Cáracca - Sigobriga - Putei - Salis - Lebinosa - Consabron - Moroin - Lamin - Marimana. Es evidente que está aludiendo a las ciudades de la vía que salía de Complutum hacia el sureste para unirse con la vía que, desde el sur, se dirigía a Caesaraugusta (Zaragoza). Basten las referencias a Segobriga (Saelices, Cuenca), a Lebinosa (Lezuza), a Consabron (Consuegra) y a Laminium (Alhambra, Ciudad Real). ${ }^{9}$

En esa lista de mansiones, la ciudad más próxima a Complutum es Cáracca, que Ptolomeo también la menciona incluyéndola dentro de las ciudades carpetanas. Teniendo presente la localización de Complutum cerca del límite oriental de la Comunidad de Madrid, todo orienta a que Cáracca se encontraba ya en el ámbito de la actual provincia de Guadalajara. Durante los acontecimientos de la guerra sertoriana, dice Plutarco que, en el 77 a.C., Sertorio sometió a los indígenas de Cáracca, ${ }^{10}$ que habitaban en cuevas. Ya hace años que Schulten dijo que corresponde con Taracena, "a 4 kilómetros al nordeste de Guadalajara, donde existen cuevas". ${ }^{11}$ Se han hecho otras propuestas de localización, ninguna de las cuales la sitúa en el ámbito de la actual Comunidad de Madrid. ${ }^{12}$

b) ¿Hay que añadir a la lista de Ptolomeo una pólis / civitas de nombre Arriaca? El Itinerario de Antonino (Itin. 436), enumerando mansiones de una vía (sur-nordeste), menciona Titulciam - Complutum - Arriaca-Caesada - Segontia. En otro pasaje del mismo Itinerario (Itin. 438), en el que se enumeran mansiones de la vía que, desde Mérida, llegaba a Zaragoza, se incluyen: Emerita - Lacipea - Leuciana-Augustobriga - Toletum - Titulciam - Complutum - Arriaca - Caesada - Segontia - Arcobriga - Aquae Bilbilitanorum. Luego Arriaca y Caesada se encontraban entre Complutum (Alcalá de Henares) y Segontia (Sigüenza). Atendiendo a la distancia media entre esas dos ciudades extremas, hay muchas dudas para poder sostener que la primera de las dos (Arriaca) se encontrara en el actual ámbito de la Comunidad de Madrid. No es imposible que Blázquez y Sánchez Albornoz tuvieran razón al ubicarla en Usanos (Guadalajara), donde han aparecido "objetos e inscripciones romanas", además de que, en ese punto, se contarían las 22 millas que separan a Complutum de Arriaca, según el Itinerario. Y tampoco es imposible que, al ser mansiones, una de ellas tuviera el rango de cabecera de civitas / pólis, aunque Ptolomeo no la mencione.

c) Desde hace años, ha habido diversas propuestas sobre la posible localización de Egelesta, en cuyo territorio había importantes salinas. Los ámbitos salineros situados en el espacio de la actual Comunidad de Madrid se encuentran en Chinchón y en las salinas Espartinas de Ciempozuelos. De estas últimas, se sabe bien que, en ellas, se obtenía la sal por ignición y que el control de las mismas fue un apoyo importante para

9 Las largas dudas sobre su localización quedan aclaradas en MoYA-MALENO 2008.

10 Plut., Sertorius 17.

11 Schulten en F.H.A. IV, 180.

12 Hurtado Aguña 2005, 16-17. González Zamora 1999 la sitúa en el yacimiento de La Merced - La Muela de Taracena; SANCho Rocher 1981, 79, en Carabaña y Abascal 1982, 79-81 en Driebes. 
las oligarquías locales ya desde la Edad del Cobre. ${ }^{13}$ Se ha resaltado también que su explotación continuó en épocas posteriores. ${ }^{14}$ Ahora bien, dada la corta distancia que hay entre Ciempozuelos, Cinchón y Titulcia, parece más bien que las salinas Espartinas de Ciempozuelos así como las de Chinchón se encontraban en el ámbito del territorio de la antigua Titulcia, lo que vendría reforzado por el hecho de presentar dos inscripciones funerarias, en una de las cuales se hace mención a la tribu Quirina, exponente de la municipalización flavia de Titulcia. ${ }^{15}$ La información sobre salinas del ámbito de la Comunidad de Madrid no apoya, pues, una localización de Egelesta en su territorio. Por lo tanto, o Egelesta se encontraba en el ámbito de la provincia de Toledo o bien en otro ámbito carpetano ajeno al de la Comunidad de Madrid. Hay indicios que orientan a que Egelesta pudo estar situada en el ámbito de Villacañas (Toledo) atendiendo al trazado de la red viaria y a las características de la sal que allí se obtenía: en bloques y, además, sal con efectos medicinales, tal como dicen los autores antiguos; ahora bien, es preciso una confirmación epigráfica y arqueológica. No hay que partir de que fuera otro error de Ptolomeo, como han sugerido otros autores. ${ }^{16}$

Luego, si no hay error en Ptolomeo, Ilurbida, Egelesta, Ilarcurís, Térmida, Mantua, Íspinon, Metercosa, Barnacis, Alternia, Paterniana y Rígusa se situarían en el ámbito de los amplios espacios del occidente de Guadalajara, de Madrid y de Toledo, en aquellos en los que no se ha documentado hasta ahora la cabecera de ninguna civitas.

Hace poco se ha llevado a cabo un minucioso trabajo en el que se ha hecho una labor de recogida sistemática de opiniones y propuestas de varios autores modernos (P. Mariana, Fita, Ambrosio de Morales, Ceán Bermúdez, Córnide, Schulten, Holder, Tovar, Müller, Bosch-Gimpera, Coello, Cortés, Fernández Guerra y la T.I.R.) sobre la localización de las ciudades carpetanas mencionadas por Ptolomeo. El resultado de su indagación es el siguiente: sobre Ilurbida, Egelesta, Ilarcurís, Varada, Térmida, Cáracca, Albora, Íspinon, Metercosa, Barnacis, Alternia, Paterniana y Rígusa todo se reduce a no se sabe o bien a sugerencias sin apoyo preciso. Sobre Titulcia, se recoge la opinión de Tovar, quien la sitúa en Bayona de Tajuña y la de la T.I.R. que la localiza en los alrededores de Aranjuez. Y sobre Mantua, se recoge la crítica de Tovar quien consideraba que las sugerencias de Müller (en uno de esos sitios: Montiel, Villamanta, Talamanca o Mondéjar) estaban "hechas al buen tuntúm”. La T.I.R. dijo que en cualquier lugar de Cuenca o Guadalajara. Últimamente se va mencionando la propuesta reciente de Stylow quien la sitúa en Perales de la Milla (Madrid). ${ }^{17}$ Sobre Toletum (Toledo) y Complutum hay opinión unánime.

Para avanzar en una real o probable localización de las cabeceras de civitates romanas en el ámbito de la actual Comunidad de Madrid, partimos de las siguientes consideraciones:

13 Delibes - Del Val 2007-2008, 794 ss.

14 Valiente Cánovas et alit 2002, 33 ss; Valiente Cánovas - Ayarzagüena 2005, 61 ss; AyarzagüEna - Carvajal 2005, 71-78; Carrasco Vayá - Hueso Kortekras 2006, 89 ss.

15 Ruiz Zapatero 2001, n66 y 67.

16 García Alonso 2007, 74 ss.

17 STYLOW 1990, 316 ss. 
-En primer lugar, creemos, contra una opinión muy generalizada, que los topónimos terminados en -ana (así, Paterniana) no vienen necesariamente precedidos de términos como mansio, statio o villa, sino que resulta válido si precede el término casa o bien el término diaeta, documentado en las Galias. ${ }^{18}$ Por lo mismo, hay que tenerlo en cuenta para la posible localización de la cabecera de Paterniana, que pudo limitarse a ser un pequeño núcleo urbano, equivalente a una statio / mansio o bien a una diaeta / casa.

-Para la delimitación de los conventus iuridici, organizados a comienzos del Imperio, no se tuvo siempre en cuenta si las civitates que dependían de cada conventus pertenecían a un mismo pueblo prerromano. De hecho, la parte nororiental de los carpetanos del actual ámbito de la Comunidad de Madrid (Complutum y otra civitas) fue incluida en el conventus Caesaraugustanus y el resto perteneció al conventus Carthaginiensis.

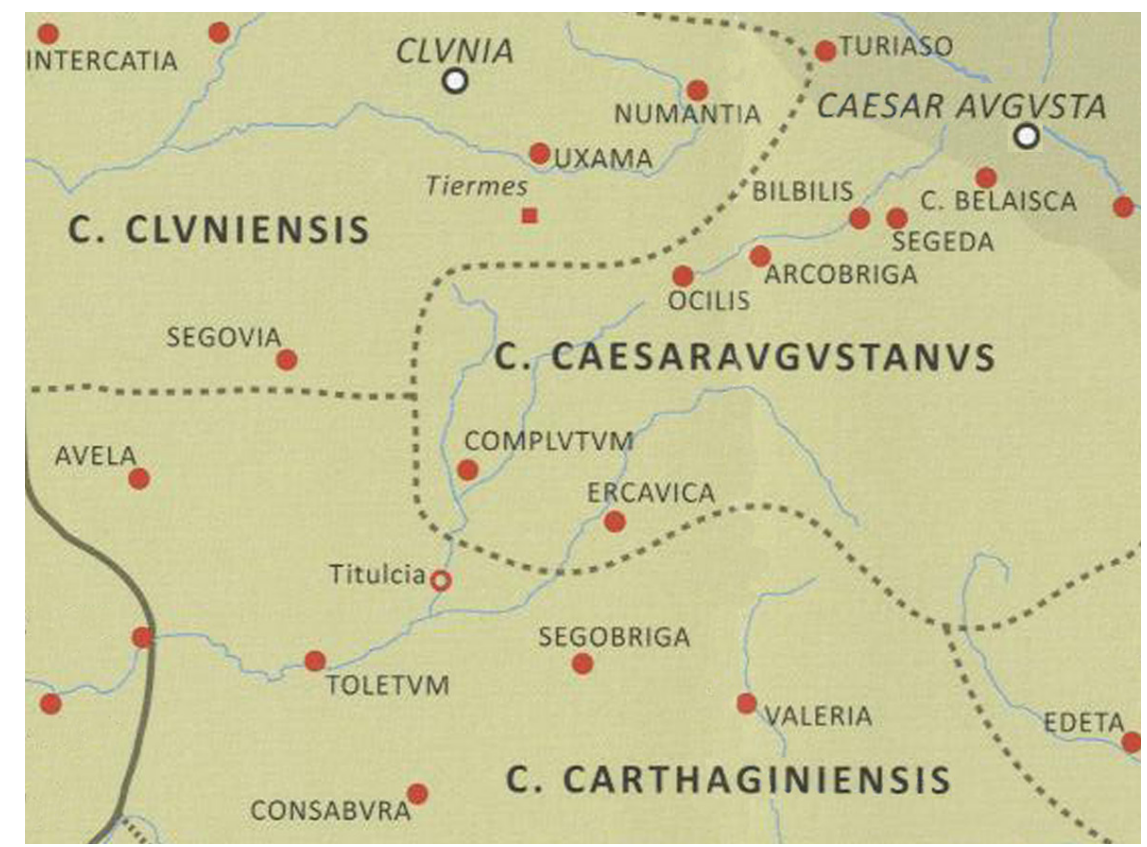

Fig. 1. Conventus iuridici del centro de la Península Ibérica (Según O. Rodríguez).

-Sabemos bien que la administración romana aplicó los siguientes criterios para reorganizar los territorios conquistados: parte de ellos (minas, canteras, salinas, pinares

18 CIL XII, $2462 \mathrm{a}-\mathrm{b}=\operatorname{ILN}$ 5, 3, $667=$ AE 2007, 926: [In ca]mpum hunc pec[ua]rium vehi / [culum] ne quis induxisse [ve]it nisi aut / [nund]dinarum cau\{a\} a [ut] hospes qui / [in diae]ta Asiciana aut [P]aconiana (?) / [hospi[tabitur vel in luc[u]m ire volet / [qui ali]ter intraverit in singula ve[hicula] /[solverit a(sses) IIIIII stercus stercul[ino des] / [tinatum] debebit [3] coni[3] / [3] dis [/ In campum hunc pecuarium ve[hiculum] / ne quis ind[uxiss] e velit nisi [aut nun] / dinarum [cau]sa au[t hospes qui in]/diaeta Asic[iana aut Paconiana (?) [hosp]i[abitur]. 
para la obtención de la pez, además de los puertos marítimos y otros espacios -así los prata militares-) quedaron como dominio directo del Estado. Las ciudades recibieron terrenos públicos y terrenos privados, al margen de que esos dominios privados pudieran tener distinta consideración si se trataba de lotes de tierra repartidos a colonos -hecho que no tuvo lugar en la Carpetania- o bien de tierras sometidas al pago de impuestos, como sucedía en las ciudades estipendiarias. Las orillas inundables de los ríos eran cosas de nadie. Los espacios dedicados al culto de los dioses eran propiedad de éstos, incluso cuando contaban con bosques u otros terrenos del templo; en este último caso, la administración de sus recursos dependía del poder civil. ${ }^{19}$

Desde esas consideraciones, podemos aceptar como territorios del Estado amplios espacios del norte de la actual Comunidad de Madrid, donde hubo explotación de minas, ${ }^{20}$ de canteras y también grandes extensiones de pinares, que se utilizaban para la explotación de la pez, que tuvo múltiples usos en la sociedad romana (para impermeabilizar recipientes muy diversos de cuero, esparto o madera como los barcos, para marcar al ganado e incluso para usos médicos -entre ellos, como los de la actual escayola-). ${ }^{21}$ Esos dominios del Estado eran alquilados a societates privadas por períodos de cinco años para su explotación a cambio de que éstas pagaran una cuota anual a las arcas públicas del Estado. Y la existencia de dominios públicos del Estado equivalía a abrir una vía para la emigración de itálico-romanos, miembros de esas societates publicanorum.

-Hay que atender también al criterio de las distancias. No tenía sentido situar dos cabeceras cercanas de civitates, ya que la población de su entorno -viviera en vici, casae o tuguria- debía acudir periódicamente a la cabecera de la civitas y los magistrados de cada una de ellas debían cumplir las funciones de inspeccionar el territorio, además de mantener al día el censo (nacimientos, actos de compra-venta), resolver múltiples pleitos locales sobre límites, sobre conflictos interpersonales... Por otra parte, la población ciudadana acudía también al núcleo urbano central los días de mercado y los días de grandes fiestas públicas. Y los medios de transporte de la época obligaban a hacer paradas tras recorrer $28-35 \mathrm{~km}$. Así, salvo espacios muy alejados, que eran ocupados por casae o por tuguria, ${ }^{22}$ el resto del territorio de la civitas, el más poblado, se encontraba en ese entorno de los $28-35 \mathrm{~km}$, donde se situaban las aldeas, vici ${ }^{23}$ también las villae durante la Antigüedad Tardía. Y cerca del núcleo urbano central, hubo también villae suburbanas.

-Otra consideración reside en la atención a los vados. Basten unos ejemplos: Complutum, Titulcia, Toletum, Albura, Caesarobrigra, Augustobriga... se encuentran junto a vados del Tajo o de sus afluentes. Y lo mismo sucede en otros muchos ámbitos; baste recordar el gran vado del Guadiana junto a Augusta Emerita o las varias ciudades del interior de la Bética, situadas junto a vados del Guadalquivir o de sus

19 Scherillo 1945, 29-34; 69 ss, 89 ss.

20 A pesar del excelente estudio coordinado por PUCHE - AYARZAGÜENA (2005) sobre minería, queda claro que falta mucho por hacer sobre la minería antigua del ámbito de la Comunidad de Madrid.

21 Mangas - Novillo 2014.

22 Sobre casa / casae y tuguria: cf. MANGas - Állvarez - Benitez 2013-14, 273 ss.

23 Entre otros, baste el testimonio bastante claro del territorio de Segobriga, Ercavica y Valeria: Cf. MaCíAs 2008, 617 ss. 
afluentes: Corduba, Astigi, Italica, Hispalis... Un buen vado permitía que las tierras del otro lado del río pudieran pertenecer a la ciudad y, por lo mismo, que la población de ambas márgenes acudiera con facilidad a resolver sus obligaciones político-administrativas, a los mercados y a las grandes festividades públicas. Disponer de un buen vado hacía posible incluso que una parte de la población de la ciudad se asentara al otro lado del río e incluso que allí se erigieran edificios públicos: baste el ejemplo de La Vega Baja de Toledo, donde, además de las necrópolis, hay villas y edificios públicos como el bien conocido circo romano. ${ }^{24}$ Colocar la cabecera de una civitas junto a un vado permitía, pues, que el río no sirviera de límite del territorio de la ciudad. A su vez, cuando se generalizaron los molinos de agua -a partir de fines del s. III d.C.-, el enclave más favorable para su situación era junto a un vado.

-No todas las cabeceras de civitates coincidían con un gran núcleo de población. Hubo "ciudades sin urbe", que cumplían las funciones básicas de un centro de administración local disponiendo sólo de un pequeño núcleo urbano. Baste el testimonio de las cabeceras de ciudades bajo la forma de forum: recordar el Forum Bibalorum y el Forum Gigurrorum, entre otros, del noroeste hispano. ${ }^{25}$ Más aún, en zonas de población dispersa -ante todo en áreas de montaña-, donde se testimonian los castella, el núcleo urbano central, que servía de cabecera de una civitas, podía ser una pequeña agrupación de casae. ${ }^{26}$

-No hay constancia de villae, fechadas únicamente a comienzos del Imperio, en la Carpetania. Con ocupación altoimperial principal y ocupación en el Bajo Imperio, destacan algunas villas suburbanas en el ámbito de Complutum como la Villa del Val u otras como la de Valdetorres del Jarama. ${ }^{27}$ La atención a la localización de villae romanas de los s. III-IV d.C. aporta poco para el análisis de las cabeceras de civitates de comienzos del Imperio. Las villae suburbanas como las cercanas a Complutum -también en el ámbito de la provincia de Toledo-y tal vez junto a otras cabeceras menores de civitates pueden contribuir a complicar el análisis cuando las cabeceras de civitates eran pequeños núcleos urbanos o sólo casae. Más aún, la implantación de una gran villa en su cercanía conduce a la mayor dificultad para localizar la cabecera de una pequeña civitas, que pudo ser abandonada pronto en la Antigüedad Tardía. Y vamos conociendo algunos casos, lo que complica la localización de muchas de ellas.

-Otro criterio a tener en cuenta reside en el trazado de la red viaria. Y siempre hay que resaltar que la información de los itinerarios antiguos (Itinerario de Antonino, Anónimo de Rávena) es limitada, ya que aluden siempre y con muchas lagunas a las vías principales. Los datos aportados por la documentación epigráfica, los referidos a hitos de las calzadas, completan la información. Y siempre hay que tener en cuenta que hubo muchas vías secundarias, no reflejadas en ningún documento epigráfico.

24 VAlero - Arcos - Molina 2010, 12 ss.: sobre intervenciones arqueológicas en la Vega Baja; RuBio 2010, 35 ss: sobre el circo romano; RuBIO - VALERO - ARCOS - MolinA 201058 ss, donde analizan una villa romana de la Vega Baja.

25 Mangas 2013, 804 ss; también en Mangas 2012, 60-64.

26 Mangas 2013, 810 ss; Mangas - Álvarez - Benítez 2013-2014.

27 SÁnchez Rascón 2006; Carrera - Martínez PÉrez 1996. 
Una propuesta razonable de las vías romanas del ámbito de la actual Comunidad de Madrid se refleja bien en el mapa adjunto.

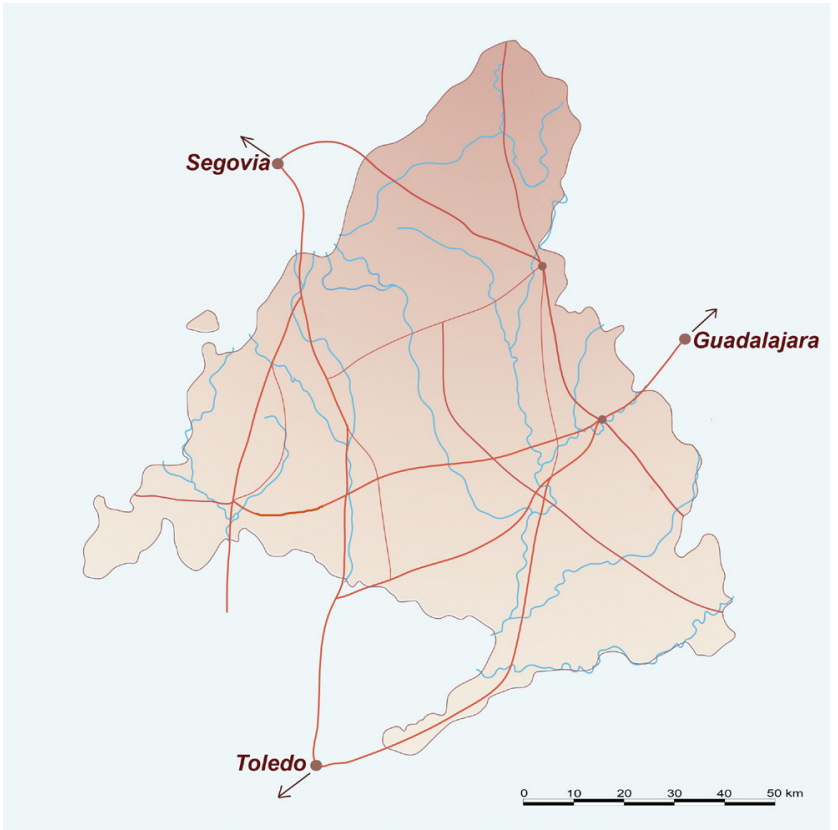

Fig. 2. Vías principales y secundarias en la Comunidad de Madrid (A partir de Caballero 2006, 44, y Ruiz Trapero 2001, 319).

-Otra fuente de información ha sido y seguirá siendo la documentación epigráfica. Para el caso que nos ocupa, cualquier información es de utilidad, pero tiene un valor excepcional -además de los miliarios- la epigrafía votiva y la referida a personajes que eran ciudadanos romanos, conocidos a través de su mención con la referencia a una de las tribus romanas.

Conviene resaltar que, dado el escaso volumen de documentos epigráficos y el mal estado de conservación de muchos de ellos, no resulta fácil, salvo para Complutum y Titulcia, el poder definir los talleres de lapicidas y el significado que se atribuía a la decoración de las estelas y aras. Más aún, las familias acaudaladas no tuvieron dificultades para traerse estelas funerarias, que se encargaron en talleres alejados de su lugar habitual de residencia. ${ }^{28}$ También nos faltan testimonios de piedras o bloques sin labrar y más aún de tablas -todavía utilizadas como estelas funerarias en la España de mediados del s. XX-, que sirvieron de estelas funerarias pintadas para las familias más pobres. Por ello, atenderemos a los textos de los epígrafes conservados.

-Hay un caso excepcional en la Península, el de los Vadinienses, en el que, sobre un conjunto de poco más de 55 inscripciones, un mínimo de 30 -es decir más del

28 Gimeno 2008, $261 \mathrm{ss}$. 
$50 \%$ - reflejan la pertenencia del mencionado a la civitas de los Vadinienses. ${ }^{29}$ Tal indicación de origo viene siendo uno de los argumentos clave para situar la cabecera de muchas civitates o bien la referencia a magistrados y augustales de una ciudad. Dejando ahora de lado Complutum y Titulcia, podemos decir que, hasta ahora, no se ha hallado ninguna inscripción en el resto del ámbito de la Comunidad de Madrid que nos permita contar con un apoyo de referencia a la origo de alguno de los mencionados ni tampoco con mención a un magistrado de la ciudad o a un augustalis / VIvir augustalis.

Desde tales consideraciones, hacemos una propuesta razonada sobre la localización de las cabeceras de civitates romanas del actual territorio de la Comunidad de Madrid, sin poner en duda la localización de las bien conocidas (Complutum y Titulcia).

\section{Mantua}

Es bien sabido que hay una ciudad homónima en el norte de Italia. Partiendo de que ni Müller, ni Tovar, ni la T.I.R. ofrecen una propuesta razonable, ${ }^{30}$ queda la sugerencia de Stylow sobre una posible identificación con Perales de Milla (Quijorna, Madrid), situada en el suroeste de Madrid, a varios kilómetros al norte de Villamanta. Perales de Milla se encuentra en relación con el pequeño río Perales y el Arroyo Palomero junto al que hay antiguas ruinas, las de la antigua Mantua, según Stylow. ${ }^{31}$ Ruiz Trapero aceptó tal localización sin discusión. ${ }^{32}$

Los apoyos de la documentación epigráfica para tal localización no son significativos, ya que conocemos hasta ahora sólo dos inscripciones funerarias. Una de ellas es una estela de granito de una magnífica factura (coronamiento con pulvinus y foculus y el cuerpo epigráfico sobre una tabula ansata enmarcada por cuatro rosetas) que presenta el siguiente texto: ${ }^{33}$

$D($ iis $) * M($ anibus $) /$ Aem(ilio) * Flaco / Eturico $(m ?) *$ mis / sicio * an(norum) * LV/ Saturninu $/ s *$ filius $*$ po $/$ suit $* s($ it $) * t($ ibi $) * t($ erra $) * l($ evis $)$

Con la alusión a missicius / missitius se aludía a un soldado romano que había cumplido o estaba a punto de cumplir su servicio militar. Estamos, pues, ante un ciudadano romano. Quedan dudas sobre si hay que entender Eturico $(\mathrm{m})$ como perteneciente a una organización suprafamiliar, lo que no era incompatible con el hecho de ser ciudadano romano, o bien entender Eturico como un segundo cognomen o la referencia a un aldea.

\footnotetext{
29 Aunque se conocen dos o tres más, baste consultar el corpus de inscripciones de la provincia de León: RABANAL - GARCÍA MARTÍNEZ 2001, n³47-402.

30 García Alonso 2007, 81-82.

31 StYlOW 1987, 336-343.

32 Ruiz Trapero 2001, 174, nº0.

33 Ruiz Trapero 2001, nº0; Stylow 1987, 322.
} 
La segunda inscripción funeraria, hallada junto a la anterior, hoy desaparecida, dice: ${ }^{34}$

$D($ iis $) * M($ anibus) / Britto / Uloq(um)/Datic(i filius)/an(norum $) * L X X / s($ it $) * t($ ibi $) *$ t(erra) *l(evis)

En este caso, el difunto, longevo, hijo de Daticus, pertenecía a una organización suprafamiliar, Uloq(um). Por más que aparezca con un solo componente onomástico, no debe olvidarse que se trata de una inscripción funeraria y, en estos casos, el texto se dirige a los familiares y convecinos que conocían bien el estatuto jurídico personal que no siempre era preciso manifestar. En nuestra opinión, ninguno de los dos textos equivale a un apoyo seguro para justificar que, en las cercanías de su hallazgo, hubiera la cabecera de una civitas.

En un reciente estudio, dedicado a la búsqueda de argumentos para localizar la Mantua Carpetanorum, se hace una detallada recogida de las valoraciones propuestas sobre la obra de Ptolomeo y sobre las propuestas diversas de los siglos XV-XVII y algunas fechas posteriores en relación con la localización de Mantua. ${ }^{35}$ Tras un análisis posterior de las informaciones arqueológicas, se concluye que el poblamiento hay que situarlo entre los siglos II-V d.C. y que ninguno de los varios yacimientos situados en las cercanías de Villamanta tiene la entidad de corresponder a un centro urbano del rango de ciudades como Complutum, Titulcia o Toletum. ${ }^{36}$

Partiendo de que la cabecera de una civitas no fue necesariamente un gran núcleo urbano, uno de nosotros, en una revisión reciente, ${ }^{37}$ sostenía que Villamanta fue la cabecera de Mantua. En la documentación epigráfica, hay mención de ciudadanos romanos pertenecientes a la tribu Quirina, lo que nos llevaría a que estamos ante un municipio latino de época de los Flavios.

A su vez, los datos arqueológicos de Villamanta y su entorno son abundantes y habrá más cuando se prospecten las cercanías del pueblo actual. Zarzalejos recoge, además de un gran alfar romano, otros 11 yacimientos de los entornos que presentan materiales arqueológicos de época romana. ${ }^{38}$

Además de esos datos, hay que atender a su posición geográfica: su situación en el suroeste de la actual provincia de Madrid no sólo servía bien de punto central para varias comunidades dispersas por su entorno, sino que era un lugar de paso obligado para caminos y vías pecuarias ${ }^{39}$ que se dirigían al ámbito del territorio de la ciudad romana de Avila / Abula, que, como es sabido, tenía ramificaciones territoriales al sur de la Sierra de Gredos. Ahora hay que añadir que Villamanta, Mantua, se encontraba cerca de la vía secundaria que, desde el sur, desde Talavera de la Reina, Caesarobri$g a$, se dirigía hacia el Norte.

34 Ruiz Trapero 2001, nº1.

35 Contreras ET ALII 1995, 399-400.

36 CONTRERAS ET ALII 1995, 400-401.

37 Mangas 2014.

38 ZARZALEJOS 2002: 15 ss; 24-26.

39 En el Museo Local se muestran algunos hitos relacionados con las vías pecuarias. 
Cuando se justificaba esta equivalencia entre Mantua $=$ Villamanta, se hacía la siguiente reflexión: con villa no hay que pensar siempre en una villa romana, ya que, desde fines de la Edad Media, al ir concediendo autonomía a muchos pueblos librándolos del poder de los nobles, era frecuente que, en las concesiones de su nuevo estatuto, se dijera que pasaban a ser "comunidades de villa y tierra" o bien "villas de por sí y para sí". En otros términos, si quitamos la parte inicial del nombre, villa, nos queda sólo manta, que no plantea problemas linguísticos para identificarlo con Mantua.

Estaríamos, pues, ante la cabecera de una civitas romana, que adquirió el grado de municipio latino en época de los Flavios, de la que dependerían varias aldeas cercanas, que nos han dado documentación epigráfica, entre las que se encontrarían Cenicientos, San Martín de Valdeiglesias, Perales de Milla, Brunete, Arroyomolinos y Móstoles, que debieron ser antiguas cabeceras de aldeas o vici, situadas en el territorio de la civitas Mantua.

La onomástica de la documentación epigráfica de Villamanta (Valerius Secundus, Avianus, L. Aelius Symachus, Aelia Pompei uxor, Aemilia Festa, Ursulus, Ammonius Varus, Festus, Fortunatus, Gaius Iulius) orienta a un elevado grado de romanización por más que haya también algún testimonio de pervivencia de organizaciones suprafamiliares como en el caso de Aplondus Dagenicum M(arci) f(ilius). ${ }^{40}$ Pero el apoyo epigráfico más claro no sólo está en el ara votiva a los dioses Lares, que refleja un elevado grado de integración en la ideología religiosa romana, sino en la inscripción funeraria del s. II sobre una tabula ansata donde es presentado un ciudadano romano, longevo, de la tribu Quirina: ${ }^{41}$

$$
\begin{aligned}
& L(\text { ucio }) * \text { Ae }(\text { lio }) * \text { Symacho / Quirina (tribu) annor/um * LXXXs }(\text { it }) * t(\text { ibi }) / t(\text { erra }) * \\
& l(\text { evis }) * \text { Aeliae * Pon/pei * ucsori } * \text { an }(\text { norum }) * X X
\end{aligned}
$$

En otra inscripción, hallada recientemente, se vuelve a repetir el testimonio de otro ciudadano romano de la tribu Quirina: ${ }^{42}$

$$
\begin{aligned}
& {[--] f(i l i u s) * \text { Quir(ina) * Severus * nepo[s ó tes...] / Sex(to) * Prisco * filio / [- - -] }} \\
& \text { eidem [q]ue dedicarunt }
\end{aligned}
$$

Por más que toda la documentación epigráfica -la antes citada- sea posterior a los comienzos del Imperio, nos está reflejando que la comunidad de Mantua y las comunidades de su entorno se encontraban en una fase avanzada de integración en la onomástica y formas de vida romana, cuando la ciudad tuvo el reconocimiento de municipio latino.

Desde los últimos meses, contamos con un nuevo apoyo: la existencia de una necrópolis de comienzos del Imperio. Las estelas funerarias, anteriores a los Flavios, fueron utilizadas en los cimientos de una gran casa (¿una villa?) de comienzos del s. III d.C., situada cerca del actual pueblo de Villamanta. No aportamos fotos ni des-

40 RUIZ Trapero 2001, nº111-118; HEp 13, 2007, nº448.

41 Ruiz Trapero $2001, \mathrm{n}^{\circ} 113$.

42 HEP 13, 2007, $\mathrm{n}^{\circ} 450$. 
cripción de las lápidas ni tampoco mencionamos los textos inéditos por respeto a los derechos de autoría de sus descubridores, pero podemos avanzar que ninguna presenta en su cabecera la alusión a los Dioses Manes, lo que nos está reflejando fechas anteriores a los Flavios.

El contexto de los vici de su entorno refuerza la pronta romanización del entorno. Ya se indicó en otro momento, que, en un santuario rural de la provincia de Toledo, cerca de la desembocadura del Arroyo Alpuébrega en el río Guadarrama, se halló un ara votiva (sin contexto arqueológico hasta ahora) que desvela que las mujeres Alboresenses Umenses, es decir de una aldea incluida en el ámbito del territorio de la ciudad de nombre Albura / Aebura / Albora ${ }^{43}$ imitaban la práctica romana de acudir a santuarios de Diana, situados fuera del ámbito de las ciudades. Diana era venerada bajo la advocación de Diana Madre, protectora de las mujeres, lo mismo que en el santuario de la Diana Nemorensis, venerada en los Montes Albanos, a donde las mujeres de Roma acudían anualmente en peregrinación.

En el territorio de Mantua se encuentra Cenicientos. En su medio rural, se halla un gran bloque de granito. Presenta una escalera en su parte posterior y, en su zona frontal, un gran bajorrelieve con tres figuras humanas de pie en actitud ritual y, en un plano inferior, la imagen borrosa de dos animales. En el lateral izquierdo de su frente, se conservan restos de un epígrafe muy erosionado, donde hay una dedicación a Diana. Partiendo de que creemos muy dudosa la lectura de la lín. 1 con un hipotético nombre personal en masculino, ofrecemos la lectura de Canto: ${ }^{44}$

\section{A(nimo) l(ibens) s(olvit votum) Sisc(inius) $Q(. .$.$) / Dianae$}

Por más que se encuentre en condiciones de difícil lectura, el gran monumento, conocido localmente como "piedra escrita", refleja la existencia de un santuario rural consagrado a Diana. Para nosotros, estamos ante un santuario semejante al antes mencionado de Aebura / Albura, un lugar a donde acudían las mujeres devotas de las comunidades vecinas. A esos datos, se puede añadir el busto de Diana, hallado en un pozo del vicus situado en Móstoles, un vicus del territorio de Mantua. ${ }^{45}$ En otros términos, nos encontramos ante el testimonio de un comportamiento religioso, que se manifiesta en otras ciudades profundamente romanizadas de Hispania: baste recordar el santuario de Diana en una cantera de Segobriga. ${ }^{46}$

Otro apoyo se deriva de la atención a la red fluvial del entorno de Villamanta, situada entre los ríos Alberche y Guadarrama con varios vados en las cercanías de Villamanta, lo que permitía una fácil comunicación con las aldeas y caseríos de sus entornos.

43 Mangas - Carrobles - Rodríguez 1992, 245 ss.

44 Seguimos la lectura de CANTO 1994, n²1, 271-296.

45 La práctica cristiana de arrojar estatuas o bustos de dioses o bien de personajes romanos a pozos va aportando cada día más testimonios: baste recordar los testimonios bien conocidos de Regina (Casa de la Reina, Badajoz).

46 Alfayé - Marco 2014, 53-56. 
Todos los datos orientan, pues, a que Mantua se localizaba en Villamanta y que pudo haber sido el centro político-administrativo de una civitas de poca entidad urbana, una civitas sine urbe.

\section{Madrid: ¿cabecera de una civitas o de un vicus?}

Olvidando las antiguas hipótesis que situaron Mantua en Madrid, quedan algunos datos sobresalientes como los siguientes:

El hallazgo de un miliario, hallado en la Puerta de los Moros apoya una realidad esperada que no viene reflejada en los textos de los itinerarios Romanos: la existencia de una vía que, desde Toletum, se dirigía al Norte para cruzar por los pasos de la Sierra de Guadarrama. Naturalmente, la existencia de tal miliario refleja la de una vía al margen de la datación de tal miliario. El miliario se ha perdido, pero se ha conservado parte del texto del mismo. Si la reconstrucción fuera correcta, se fecharía entre el 10 de diciembre del 99 o el 10 de diciembre del año 100 d.C., es decir alusivo al emperador Trajano. El texto transmitido dice: ${ }^{47}$

[Imp(erator) Nerva / Caesar Aug(ustus) / Traianus] / Ger(manicus) Po[n]tif(ex) / [Max(imus) trib(unicia) / pot(estate) III P(ater) P(atriae) co(n)s(ul) II]/ ------

Otro conjunto de inscripciones romanas, halladas en los restos del antiguo poblado (en los bancos del Manzanares, junto al Puente de los Franceses, en lienzos de la muralla, en las escaleras de una casa cercana a la muralla, en los escalones de Santa María de la Almudena, en la puerta de Guadalajara... $),{ }^{48}$ todas funerarias, desvelan la reutilización de las mismas tras ser tomadas de una necrópolis cercana. Hubo, pues, una población estable durante época romana. Más aún, el tipo de onomástica (Aemilia Eutychia, Lucius Albinus P(...), Gaius, Lucius Domitius Caucinus, Lucius Domitius Paternus, Lucius Valerius Latinus, Caecilia, Caius Valerius Lucanus) desvela un elevado grado de integración en el modelo social romano. Y la inscripción, ya cristiana, de época visigoda (año 715), hallada en un nicho del claustro de Santa María de la Almudena, es otro testimonio epigráfico de la pervivencia del anterior poblamiento romano.

En el ámbito y los entornos de la actual ciudad de Madrid, se han hallado restos arqueológicos que desvelan alguna modalidad de poblamiento romano (Casa de Campo: una villa; Carabanchel: una villa; Villaverde Bajo: una necrópolis; La Gavia: poblado carpetano; Vallecas: una villa). Los restos de villae son de épocas avanzadas del Imperio. El Cerro de La Gavia (Villa de Vallecas) es un yacimiento de gran entidad; ahora bien, las últimas investigaciones hablan de su urbanismo como característico de la Segunda Edad del Hierro, lo que no orienta a pensar que pudiera ser la cabecera de una civitas romana, al menos en los comienzos del Imperio. ${ }^{49}$

47 Ruiz Trapero 2001, $\mathrm{n}^{\circ} 129$.

48 Ruiz Trapero 2001, nº73-79.

49 Morín Pablos et alit 2009, 233 ss; Quero et alit 2005. 


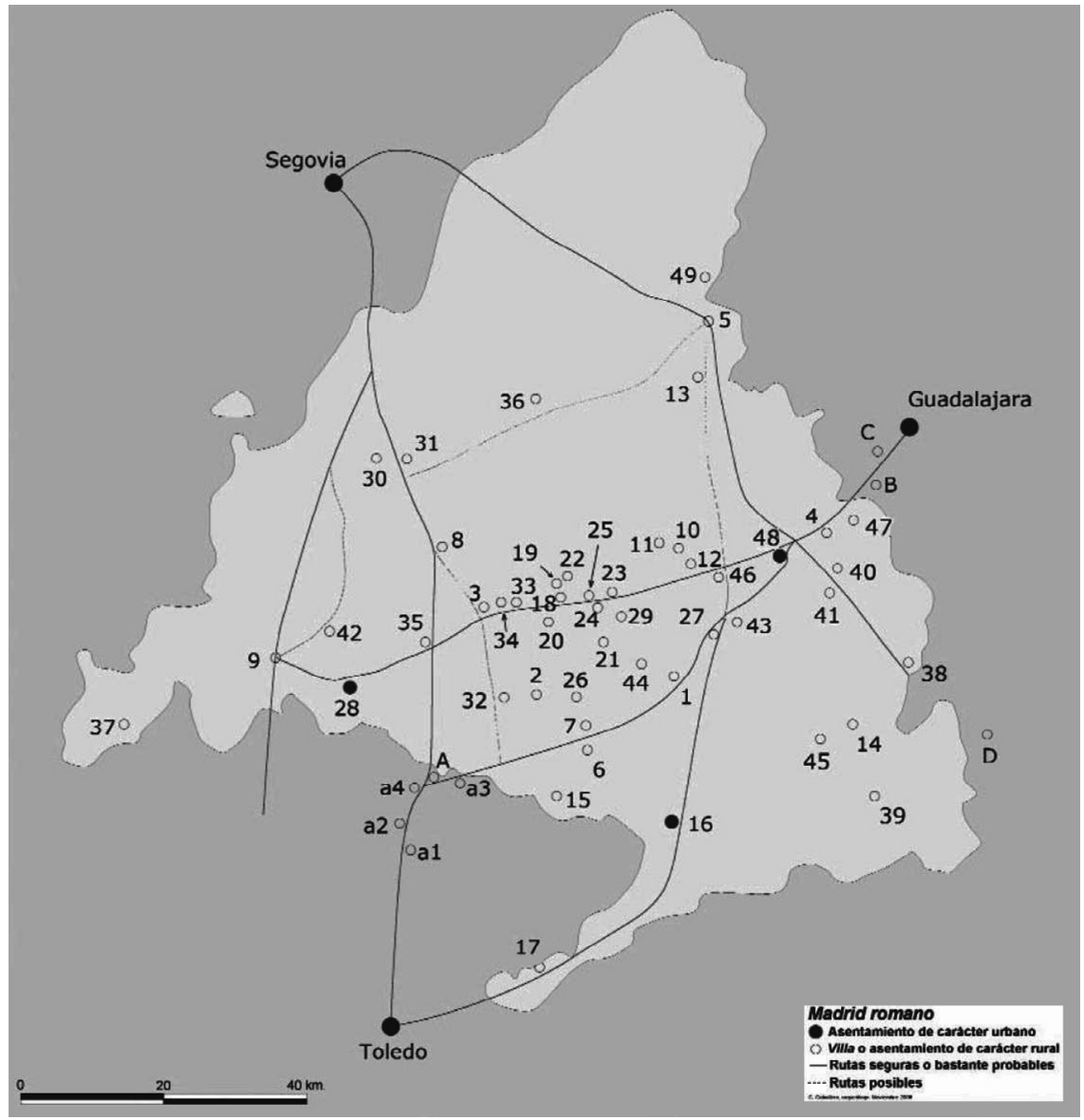

Fig. 3. Vías y principales asentamientos urbanos y rurales del Madrid romano. 1: La Torrecilla, Getafe. 2: Arroyo Culebro. 3: La Pingarrona, Boadilla. 4: El Val, Alcalá de Henares. 5: Talamanca del Jarama. 6: La Indiana, Barrio del Prado, Pinto. 7: Tinto Juan de la Cruz, Pinto. 8: Despoblado de Villarejo, Villanueva de la Cañada. 9: El Santo, Aldea del Fresno. 10: El Rasillo, Barajas. 11: El Guijo, Barajas. 12: El Encadenado, Barajas. 13: Valdetorres del Jarama. 14: Carabaña.

15: Torrejón de Velasco. 16: Titulcia, Ciempozuelos. 17: Villamejor, Aranjuez. 18: Meaques,

Madrid. 19: Retamares, Madrid. 20: Carabanchel, Madrid. 21: Villaverde, Madrid. 22: Ciudad Universitaria, Virgen de África, Madrid. 23: Ventas del Espíritu Santo, Madrid. 24: Santiago el Verde, Madrid. 25: Vistillas, Madrid. 26: c/ Sur, Jetafe. 27: Velilla de S. Antonio. 28: Villamanta.

29: Vallecas, Madrid. 30: Monesterio, San Lorenzo de El Escorial. 31: El Beneficio, Collado Mediano. 32: Móstoles. 33: Viña Machaca, Boadilla del Monte. 34: Carretera de los Pantanos, Boadilla del Monte. 35: Quijorna. 36: Colmenar Viejo (Ter. Augustalis). 37: Piedra Escrita, Cenicientos. 38: Ambite. 39: Villarejo de Salvanés. 40: Villalbilla. 41: Valverde de Alcalá. 42: Perales de Milla. 43: Arganda del Rey. 44: Cerro de la Gavia, Madrid. 45: Perales de Tajuña. 46: San Fernando de Henares. 47: El Llano de la Horca, Santorcaz. 48: Alcalá de Henares. 49: Dehesa de la Oliva, Patones. Fuera del territorio madrileño: A: Carranque. B: Azuqueca de Henares. C: Alovera. D: Driebes, al -a4. Carranque, villae (C. Caballero 2006, 44). 
Teniendo presente una de las observaciones iniciales, la de que, en época romana, hubo "ciudades sin urbe" y, a su vez, la posición geográfica del antiguo poblamiento en relación con las vías -testimonio de un miliario-, la cercanía a un vado del Manzanares y la distancia con las cabeceras de las ciudades romanas localizadas (Complutum, Titulcia, Mantua), no es imposible que el poblado romano de Madrid equivaliera a la cabecera de una civitas romana. Ahora bien, como no hay datos definitivos para garantizarlo, nos quedamos con la seguridad de que ese poblado romano de Madrid fue como mínimo un antiguo vicus, que cumplía a la vez las funciones de mansio en la vía que venía desde Toletum para dirigirse al norte.

\section{Cabecera en el nordeste de la Comunidad de Madrid}

Por más que no venga reflejada en los itinerarios romanos, no parece haber duda sobre la existencia de una vía que cruzaba la Sierra de Guadarrama por el Puerto de la Fuenfría.$^{50}$ Los apoyos más claros se derivan de los dos miliarios hallados a unos 700 metros del puente de Santa Catalina.

Del primero de ellos, fechado en el s. IV, se conserva el siguiente texto: ${ }^{51}$

- - - - /IP [- - ] / NOB(ilissimus) / CAES(ar) / - . . . -

El segundo, fechado en época de Decio, tampoco está completo. Atendiendo a la distancia entre el lugar del hallazgo y Segovia, se ha calculado que van bien las XVII millas indicadas en el texto que se conserva; se ha ofrecido la siguiente reconstrucción del mismo: ${ }^{22}$

- - - - / [- - ? vias et pontes temporis vet] ustate cor /[ruptos restituerunt curante Q.] Decio leg(ato)*. Aug(usti)*Pro *Pr(aetore)*/m(ilia)* p(assum) XVII

Ambos miliarios tienen una fecha alejada de los comienzos del Imperio, pero desvelan la existencia de una antigua vía, ya muy utilizada, en la que, en época de esos miliarios, tuvieron que hacer reconstrucciones de puentes (pontes temporis vetustate corruptos restituerunt), que se encontraban sobre vados.

En ese ámbito se encuentra el Monasterio de El Paular, para cuya construcción se debieron utilizar materiales romanos de sus proximidades; dentro del Monasterio, se halla la inscripción siguiente: ${ }^{53}$

\section{$L($ ucius $) *$ Acilius / Maxsumi / f(ilius) $* Q($ uirina $) *$ Maxs/uminus / an(norum) *XXXIII}

50 MARINÉ 1990, 327 ss.

51 StYLOW 1994, 582; HEp 5, 1995, nº551; RUIZ TraPero 2001, nº 126.

52 Stylow 1994, 581-590; HEp 5, 1995, nº550; Ruiz Trapero 2001, nº125. Cf. Solana 2014, 340 ss, sobre los usos de refecit y perfecit en los miliarios.

53 MANGaS 1988, 211-213; HEp 2, 1990, nº457. 
Con la onomástica romana y la alusión a un ciudadano romano de la tribu Quirina, a la que pertenecieron los municipios flavios de la Carpetania, se refuerza la idea de la posible existencia de la cabecera de una civitas en ese entorno del nordeste de la Comunidad de Madrid.

Hay un yacimiento arqueológico de grandes dimensiones en ese entorno. Lo ha puesto en evidencia una antigua excavación arqueológica, realizada en 1956 y 1957. Nos referimos a la que se llevó a cabo en la Dehesa de la Oliva (Patones, Madrid). Estamos ante los restos de un yacimiento que no responde a las áreas superficiales de los oppida de la Hispania céltica. ${ }^{54}$ Las excavaciones han dado como resultado un gran núcleo urbano, amurallado, con una superficie de 10 ha en su parte superior, llamada acrópolis, y de 16-18 ha al oeste de la anterior. Especialmente significativo resulta el advertir que los materiales hallados parecen desvelar una ocupación ininterrumpida desde el s. II a.C. hasta inicios del s. V d.C. Posteriormente se han llevado a cabo otras intervenciones arqueológicas en el cerro de la Dehesa de la Oliva, que ofrecen una visión más matizada sobre el asentamiento. Muñoz Carballo y Cuadrado reanudaron la investigación en la zona de la acrópolis en los años 1974 y $1980,{ }^{55}$ que no se retomaron hasta 1990 con un equipo más amplio de investigadores, coordinado por Montero. ${ }^{56}$ En el 2005, se retomaron los trabajos arqueológicos con la inclusión del asentamiento en el Plan de Yacimientos Visitables, en los que han participado diversas empresas; los resultados permanecen inéditos. Una reciente revisión de todas estas intervenciones a cargo de Vigil-Escalera plantea nuevas hipótesis sobre el yacimiento: la más importante y sugerente reside en proponer que la Dehesa de la Oliva pudo no tener una ocupación continuada entre la República Tardía y el Bajo Imperio; su población se habría trasladado al llano contiguo antes de mediados del s. I d.C. y volvió a su ubicación originaria en los comienzos del s. V d.C. ${ }^{57}$ A pesar de tales cambios, queda claro el valor de ese centro cuando nos consta que siguió habiendo una ocupación medieval. ${ }^{58}$ Por lo mismo, todos los indicios orientan a que tal núcleo urbano debió de cumplir la función de caput civitatis antes y en época de Augusto, como en años posteriores.

Una vez abandonado, el espacio del yacimiento se utilizó como necrópolis y, fue objeto de una nueva ocupación tras la Reconquista, cuando, sirviéndose de los materiales antiguos, se construyó la iglesia románico-mudéjar de la Virgen de la Oliva. A pesar de las prisas con las que tuvo que realizarse la excavación inicial ante la urgencia por comenzar a construir la Presa del Atazar así como por el sistemático expolio de sus restos, muchos de ellos reutilizados en Patones de Abajo, la planta demuestra muchos signos constructivos que responden a los modelos de muchas ciudades romanas: así, el trazado ortogonal de sus calles, dotadas de aceras, los canales de desagüe y algunos edificios arrasados (¿edificios públicos civiles o templos?) y el que parece

54 Tal como los definen Almagro-Gorbea - Dávila 1995, 289-230.

55 Sobre tales excavaciones, contamos con informes de MuÑoz CARballo 1974; 1980; 1994.

56 Montero ET ALII 2007, 120-130.

57 Hay otros testimonios de poblados prerromanos, situados junto a donde más tarde estuvo la cabecera de una civitas: Cf. BAQUEDANO ET ALII 2007; AzCÁRRAGa 2007.

58 Vigil EsCalera 2012, 239 ss. 
destinado a albergar pequeñas tiendas. Su trazado urbano muestra, por el momento, al menos ocho calles paralelas en dirección Oeste-Este y tres Norte-Sur, un posible porticado monumental en uno de los accesos a la urbe, que parece contar con un espacio residencial y otro público en el que destacan los restos de un edificio de $60 \mathrm{~m}$ de largo de planta tripartita. ${ }^{59}$

Tal yacimiento reúne las condiciones de encontrarse junto a un antiguo vado del río Jarama y en un punto estratégico para el control del paso entre las dos submesetas. Habrá igualmente que analizar detenidamente si las canteras de pizarra de sus proximidades tienen un origen de explotación en época romana, lo que reforzaría el valor económico de ese centro.

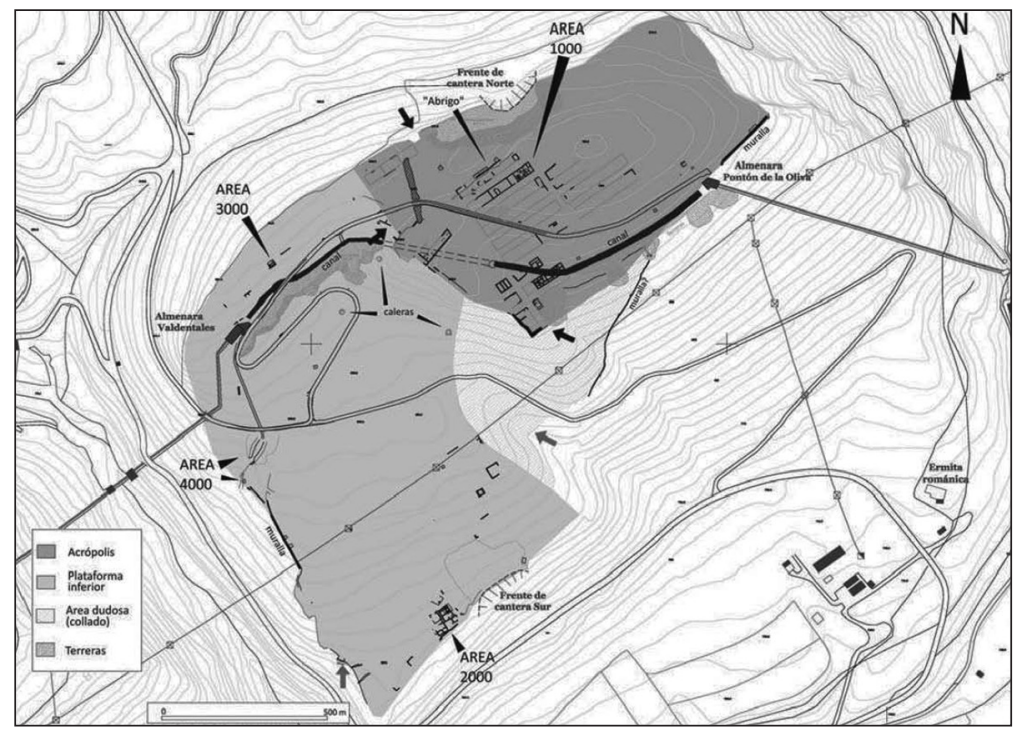

Fig. 4. Planta general del yacimiento de La Dehesa de la Oliva con indicación de las áreas exploradas y distribución zonal (Vigil Escalera 2012, 243; fig. 11.6).

La documentación epigráfica no ofrece por el momento un gran apoyo, ya que estamos ante inscripciones funerarias, casi todas de factura torpe, con una onomástica muy común (Mercator, Primigenia, Caecilius Cusa, Eros, Iulius, Gaius Valerius Marcelus, Marcela) $:{ }^{60}$ una procede de Torrelaguna, dos de Talamanca del Jarama y una de La Cabrera. Mayor importancia tiene la manifestación de un culto a Mars. Inicialmente pensamos que debía tratarse de un Marte agrario, acorde con las actividades prioritarias de las comunidades de su entorno, pero queda abierta la vía para entender que estamos ante un Marte pacificador de las tensiones sociales en las comunidades romanas. Tal dedicación a Marte fue hecha por un personaje que no indica su tribu, pero que debió de ser la Quirina por el carácter de su onomástica con tria

59 Vigil Escalera 2012, 254-255.

60 Ruiz Trapero $2001 \mathrm{n}^{\circ} 96$; 97; 102; HEp 12, 2006, n³44. 
nomina. Sería así otra confirmación de la municipalización en época de los Flavios. Nos referimos a la siguiente ara votiva, hallada en Talamanca del Jarama, que puede fecharse entre fines del s. I - inicios del s. II d.C.: ${ }^{61}$

\section{Marti / sacrum / C(aius) * Aburius / Lupus /v(otum) $*$ s(olvit $) * l($ ibens $) * m($ erito $)$}

Debe resaltarse que, además de las aras consagradas a Marte, procedentes de Complutum, hay otra dedicación a Marte en el noroeste de la Comunidad de Madrid, lo que refuerza la importancia de esta divinidad romana para las antiguas comunidades de esta zona. Por el momento, no tenemos indicios que orienten a fenómenos de sincretismo entre el dios romano Marte y divinidades prerromanas de análoga advocación. ${ }^{62}$

Atendiendo, pues, a las distancias en relación con otras cabeceras y a las vías, se espera la cabecera de una civitas en el nordeste del actual territorio de la Comunidad de Madrid. No hay todavía garantías plenas para sostener dónde se situaba. Ahora bien, la documentación arqueológica ofrece toda probabilidad de que coincidiera con los restos que se nos han conservado de La Dehesa de la Oliva (Patones). Se añade otro argumento en su favor si atendemos a los vados. En todo caso, hay que esperar a que un nuevo hallazgo nos garantice esa probabilidad y nos dé el nombre de la misma. En este caso, habría que pensar que quedó incluida en el conventus Caesaraugustanus.

\section{Cabecera de civitas en el noroeste de la Comunidad de Madrid}

En el noroeste de la actual Comunidad de Madrid, donde confluyen la vía del Occidente y la del Centro que se dirigían a cruzar el Puerto de Guadarrama, hay testimonios significativos de época romana en los actuales pueblos de Galapagar, Collado Villalba, Alpedrete, San Lorenzo del Escorial y Cercedilla, además de otros algo más distantes en Manzanares el Real y Colmenar Viejo.

Se justifica bien la existencia de tales vías no sólo por la necesidad objetiva sino por la referencia al hallazgo de un miliario cerca de Torrelodones y de tres hitos en el término de Guadarrama; éstos últimos están hoy desaparecidos sin haberse conservado el texto de los mismos. ${ }^{63} \mathrm{El}$ miliario hallado en Galapagar, fechado entre el 213-217 d.C., aporta otro apoyo sobre la existencia de una vía romana, a pesar de que el miliario se feche en época del emperador Caracala. ${ }^{64}$

Otro apoyo significativo, que puede contribuir a fijar el límite del territorio de dos civitates se halló a $5 \mathrm{~km}$ de Colmenar Viejo cerca de la actual carretera que se dirige a Guadalix de la Sierra. En este caso, estaríamos ante una probable demarcación de la

61 Ruiz Trapero 2001, $\mathrm{n}^{\circ} 95$.

62 Muchos testimonios de tales sincretismos han sido analizados en diversos trabajos recientes: cf. BOUQUIER ET ALII 2006.

63 Ruiz Trapero 2001, nº127-128.

64 HEp 11, 2005, n³25. 
parte oriental de la civitas que se encontraba en el noroeste. Sólo se conserva la línea primera del texto antiguo, donde es posible leer: ${ }^{65}$

\section{TER(minus) * AUG(ustalis)}

En las noticias conservadas sobre los itinerarios romanos, se aporta la referencia de Miacum, una mansio entre Complutum y Segovia que se viene situando al norte de Madrid en dirección a Guadarrama. Ello refuerza la idea de la existencia de una vía principal.

El interés por localizar Miaccum viene estando presente desde los estudios de A. Blázquez sobre las vías romanas de Hispania. En los últimos años, desde que se ha atendido también a los restos arqueológicos conocidos, además de a los documentos epigráficos y a la distancia marcada por los itinerarios antiguos (XXIV millas entre Miaccum y Segovia), se vienen abandonado antiguas propuestas como las de situar Miaccum en las proximidades de Madrid, en la Casa de Campo, idea apoyada en la cercanía lingüística con la del Arroyo Meaques, así como las de Las Rozas, Collado Villalba y Alpedrete. ${ }^{66}$ Se va imponiendo la tesis de que hay que localizarlo en las cercanías de Guadarrama. Las hipótesis y los razonamientos son varios e importantes: así, el atender a los numerosos vestigios de un asentamiento romano en San Lorenzo de El Escorial, que cuenta además con un cercano enclave celtibérico en altura. ${ }^{67} \mathrm{Se}$ ha precisado también que el yacimiento de Monesterio, además de presentar muchos restos arqueológicos de varias épocas romanas, está asociado a una estructura doméstica que incluía un hypocaustum; incluso se abre la posibilidad de que hubiera varias posadas próximas. ${ }^{68}$ La observación sobre los baños es importante, ya que fue frecuente, en fechas muy distintas, el que las mansiones contaran con baños. ${ }^{69}$ Hay quien resalta la posibilidad de considerar que Miaccum coincidía con El Beneficio. ${ }^{70}$ Otros lanzan la hipótesis de hacer coincidir Miaccum con Alpedrete. ${ }^{71}$

Ahora bien, podemos sintetizar diciendo que las diversas hipótesis o propuestas de los últimos años coinciden en que faltan pruebas definitivas para una segura localización de Miaccum. En todo caso, si se confirma que Miaccum se localiza en alguno de los enclaves propuestos, queda pendiente el problema de que tal topónimo no coincide con el nombre de ninguna de las póleis / civitates mencionadas por Ptolomeo. ¿Estamos ante una mansio, Miaccum, y ante otro enclave, tal vez no lejano, de una civitas sine urbe?

No hay, pues, un apoyo definitivo para garantizar el enclave central de esa civitas del noroeste de la Comunidad de Madrid por más que existan todas las probabilidades de su localización en ese ámbito atendiendo a las vías y a las distancias ante otras cabeceras de civitates. El que la documentación epigráfica nos desvele que había gru-

65 Stylow 1990, 317 ss; Ruiz Trapero 2001, nº70; HEp 4, 1994, nº803.

66 Caballero et alit 2003, 136-137; CABallero 2006, 43; JimÉnez Guijarro 2006, 54-56.

67 CABallero ET ALII 2003, 137.

68 Caballero 2006, 137.

69 Morales Segura - Segura Graiño 2013, 309 ss.

70 JimÉnEZ GUIJARRo 2006, 54-56.

71 Beltrán Ortega 2006, 75. 
pos de comunidades que mantenían la forma de las organizaciones suprafamiliares, definidas a través de los genitivos de plural en -um que se documentan en la referencia a varios particulares, no es obstáculo para poder hablar de una romanización y latinización profunda, ya que se presentan junto a onomástica romana.

Hay datos sobresalientes como son las dos aras votivas de Collado Villalba a dioses romanos, que reflejan un elevado grado de integración en la cultura religiosa romana. Nos referimos al ara consagrada a los Lares, hallada cerca de Alpedrete y Collado Villalba: ${ }^{72}$

\section{Ami / a Ael / lariq(um)/Lari / bus}

La otra ara votiva, hallada también cerca de Alpedrete y Collado Villalba dice lo siguiente: ${ }^{73}$

Cantaber / Elguism / iq(um) * Luci * f(ilius) / Marti / Magno / v(otum) *s(olvit) a(nimo) *l(ibens)

Como no hay apoyos para pensar en un Marte con advocación militar, ni tampoco es segura su advocación de divinidad protectora de la agricultura, creemos poder estar ante un Marte pacificador de los conflictos sociales, como en los otros casos antes citados de Marte. A veces, ese Marte fue el resultado de un sincretismo con una divinidad local de tradición céltica, como sucedió con frecuencia en las Galias, ${ }^{74}$ pero no hay apoyos para entender así el ara de Alpedrete y Collado Villalba. Estamos, pues, ante una manifestación de la penetración de la cultura religiosa romana.

Partiendo, pues, de la consideración de que corresponde la existencia de una cabecera de civitas para ese ámbito del noroeste de la Comunidad de Madrid, no es imposible que estuviera en o cerca de la finca Monesterio (San Lorenzo de El Escorial) o bien en Collado Villalba. Como apoyo de esta segunda opción contamos con el hito terminal, con el trazado de las vías romanas y con las manifestaciones religiosas que desvelan un elevado grado de integración en la cultura romana. Por más que falte mucho por hacer en el ámbito arqueológico, siempre hay que tener presente que podemos estar ante la cabecera de una civitas, coincidente con un pequeño núcleo urbano.

\section{Conclusiones}

Dejando ahora de lado la atención a Complutum y a Titulcia, que son objeto de otras ponencias, podemos concluir diciendo:

-Que la antigua Mantua tenía su cabecera en Villamanta.

72 RUIZ TRAPERO 2001, $\mathrm{n}^{\circ} 68$.

73 Ruiz Trapero 2001, no69.

74 Cf. Kleine Pauly, 1046-1049: Mars. Ahora contamos con una información más extensa en los muchos trabajos de la obra colectiva, coordinada por BROUQUIER ET ALII 2006. 
-Que otra cabecera de civitas se encontraba, con toda probabilidad, en las ruinas de La Dehesa de la Oliva (Patones) y otra en o cerca de Collado Villaba o de San Lorenzo de El Escorial.

-Que no es imposible que los restos arqueológicos y epigráficos hallados en Madrid estén reflejando la existencia de otra cabecera de civitas.

-Que habrá que seguir esperando el hallazgo de nuevos documentos epigráficos que confirmen esas altas probabilidades así como los nombres de algunas de esas civitates.

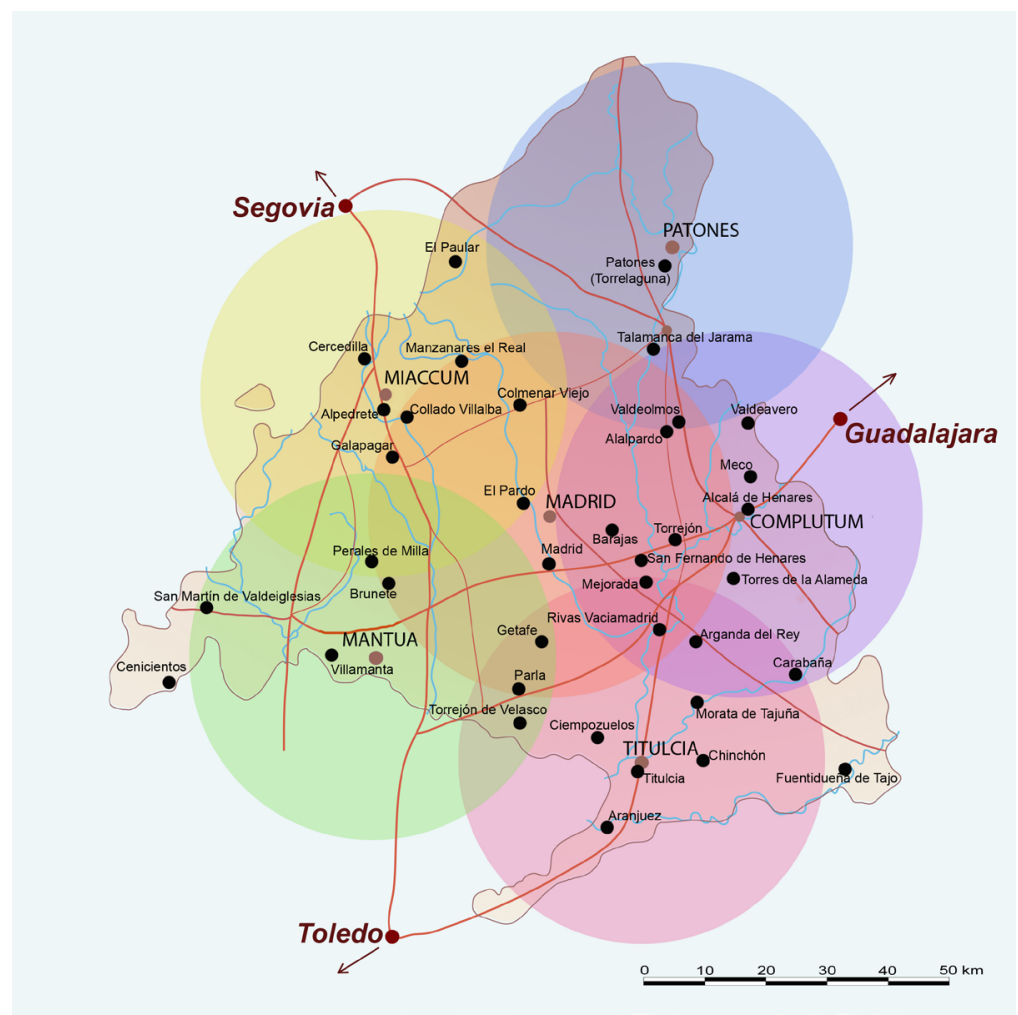

Fig. 5. Localización de inscripciones y propuesta de ubicación de cabeceras de ciudades romanas y su territorio (A partir de Caballero 2006, 44 y de Ruiz Trapero 2001, 317).

\section{Bibliografía}

AA.VV. (1990): Simposio sobre la red viaria en la Hispania romana, Zaragoza.

Abascal, J. M. (1982): Vías de comunicación romanas de la provincia de Guadalajara, Guadalajara.

Abascal, J. M. - EsPinosa, U. (1989): La ciudad hispano-romana: privilegio y poder, Logroño. 
AlfaYÉ, S. - MARCO, F. (2014): "Santuarios en canteras y romanización religiosa en Hispania y Gallia”, [en] J. Mangas - M. A. Novillo (eds.), Santuarios suburbanos, Madrid, 53-86.

AlFöLDY, G. (1987): Römisches Städtewesen auf der Neukastilischen Hochebene, Heidelberg. ANDREU, J.

(2004): Edictum, Municipium y Lex: Hispania en época Flavia (69-96 d. C.), BAR International Series $n^{\circ} 1293$, Oxford.

(2008): "Municipalización y vida municipal en las comunidades romanas de la Meseta Sur", [en] G. Carrasco (coord.), La romanización en el territorio de Castilla-La Mancha, Cuenca, 225-260.

Almagro-Gorbea, M. - Dávila, A. F. (1995): "El área superficial de los oppida en la Hispania Céltica", Complutum 6, 209-233.

ARIAS, G. (2004): Repertorio de caminos de la Hispania romana, Ronda (2a ed.).

ArÉvAlo, A. (2008): “Aprovisionamiento y circulación monetaria en la Meseta Sur durante la época romana", [en] G. Carrasco (coord.), La romanización en el territorio de Castilla-La Mancha, Cuenca, 127-182.

Ayala, A. (1982): "La estela funeraria del Castro del Pontón de la Oliva", Boletín de la Asociación Española de Amigos de la Arqueología 15, 30 ss.

AyarzagüEna, M. - CARvajal, D. (2005): "Sistemas de explotación en las salinas Espartinas”, [en] O. Puche - M. Ayarzagüena (eds.), Minería y metalurgia históricas en el Sudoeste europeo, SHA, Madrid, 71-78.

AzCÁRraGA, S.

(2007): "El inicio de la romanización en la región madrileña: nuevas perspectivas para la investigación", [en] AA.VV., Estudios sobre la Edad del Hierro en la Carpetania. I. (=Revista Zona Arqueológica 10), 374-394.

(2014): "Nuevos datos sobre la romanización de la Carpetania centro-septentrional", I Simposio sobre los Carpetanos. Arqueología e Historia de un pueblo en la Edad de Hierro (12-14, marzo, 2013), Alcalá de Henares, 435-445.

Baquedano, E. - Contreras, M. - Märtens, G. - Ruiz Zapatero, G. (2007): “El oppidum carpetano de El Llano de la Horca (Santorcaz, Madrid)", [en] A. Dávila (ed.), Estudios sobre la Edad del Hierro en la Carpetania. (=Revista Zona Arqueológica 10), vol. II, Madrid, 374-394.

Beltrán Ortega, A. (2006): "Vías y restos romanos en la Sierra de Guadarrama", Nuevo Miliario 3, 65-78.

Bravo, G. (2014): "Notas sobre el área urbana de algunas ciudades hispanorromanas. Una nueva propuesta", [en] R. Cid - E. García Fernández (eds.), Debita verba. Estudios en Homenaje al profesor Julio Mangas, vol. II, Oviedo, 15-29.

Brouquier-Redde, V. - Bertand, E. - Chardenoux, M-B. - Gruel, K. - L'Huillier, Cl. (eds.) (2006): Mars en Occident (Actes du Colloque International), Rennes.

Caballero, C. (2006): "Madrid romano: nuevos puntos de vista", Nuevo Miliario 3, 37-48.

Caballero, C. - Fernández, S. - Martín, A. (2001): "Miliarios de la vía 24 del Itinerario de Antonino en la Sierra de Guadarrama", Larouco 3, 135-146.

CAnto, A. (1994): "La piedra escrita de Diana, en Cenicientos, Madrid, y la frontera oriental de Lusitania", Cuadernos de Prehistoria y Arqueología de la U.A.M 21, 271-278. 
CARrasco, G.

(2008a): "La intervención romana en Castilla-La Mancha: la anexión del territorio", [en] G. Carrasco (coord.), La romanización en el territorio de Castilla-La Mancha, Cuenca, 13-32.

(2014): "Las fuentes literarias y las vías romanas en la Meseta Sur", [en] R. M M Cid LópezE. García Fernández (eds.), Debita verba. Estudios en Homenaje al profesor Julio Mangas, vol. II, Oviedo, 273-282.

Carrasco, G. (coord.)

(2007): Los pueblos prerromanos en Castilla-La Mancha, Cuenca.

(2008): La romanización en el territorio de Castilla-La Mancha, Cuenca.

CArrasco Vayé, J. F. - Hueso Kortekras, (2006): "Etnosal: un intento de recuperar la memoria salinera de Castilla-La Mancha”, Oppidum 2, 85-106.

Carrera, E. - Martín, A. - PÉrez, A. (1995): Las villas romanas de Madrid. Madrid en época romana, Madrid.

Castillo, E. (2008): "La Península Ibérica según Plinio el Viejo”, [en] J. Mangas - M. A. Novillo (eds.), El territorio de las ciudades romanas, Madrid, 31-71.

Cid López, R. Ma - García Fernández, E. (eds.) (2014): Debita verba. Estudios en Homenaje al profesor Julio Mangas, vols. I-II, Oviedo.

Contreras, M. - JimÉnez, C. - Martín, A. (1995): “Aproximación al estudio de la Mantua Carpetanorum de Ptolomeo: Nuevas aportaciones arqueológicas para su localización", [en] Actas. XXII Congreso Nacional de Arqueología, Vigo, 399-404.

Delibes, G. - Del Val, J. (2007-2008): “La explotación de la sal al término de la Edad del Cobre en la Meseta Central española. ¿Fuente de riqueza e instrumento de poder de los jefes Ciempozuelos", Veleia 24-25, 791-811.

Durán Fuentes, M. (2008): "Detalles constructivos de los puentes romanos y ejemplos en Castilla-La Mancha", [en] G. Carrasco (coord.), La romanización en el territorio de Castilla-La Mancha, Cuenca, 183-223.

GALSTERER, H. (1971): Untersuchungen zum römischen Städtewesen auf der Iberischen Halbinseln, Berlin.

Gamallo, J. L. - Gimeno, H. (1990): "Nuevas inscripciones de Villamanta (Madrid)”, Gerión 8, 287-298.

García Alonso, J. L.

(2003): La Península Ibérica en la Geografia de Claudio Ptolomeo, Vitoria. (2007): "La toponimia en el territorio de Carpetania" [en] G. Carrasco (coord.), Los pueblos prerromanos en Castilla-La Mancha, Cuenca, 67-99.

GARcía Fernández, E. (2001): El municipio latino. Origen y desarrollo, Madrid.

Gimeno, H. (2008): "Paisajes epigráficos en el espacio romano de la Comunidad de CastillaLa Mancha”, [en] G. Carrasco (coord.), La romanización en el territorio de Castilla-La Mancha, Cuenca, 261-338.

Gimeno, H. - Stylow, A. U. (1994): “Ara del Pontón de la Oliva”, Boletín de la Asociación Española de Amigos de la Arqueología 34, 53 ss.

GonzÁlez-Conde, Mª P. (1987): Romanidad e indigenismo en Carpetania, Alicante.

GonzÁLEz, Ma C. (1986): Las unidades organizativas indígenas del área indoeuropea de Hispania, Vitoria. 
GonzÁlez Román, C. (2001): “Ciudad y poblamiento romano en la provincia de Granada durante el Alto Imperio", Habis 32, 271-296.

GonzÁlez Román, C. - Morales, E. (2008): "El ager del municipium Florentinum Iliberritanum (Granada)", [en] J. Mangas - M. A. Novillo (eds.), El territorio de las ciudades romanas, Madrid, 249-277.

HERNANDO, $\mathrm{M}^{\mathrm{a}} \mathrm{R}$.

(2008): “Ávila: una ciudad con vocación ganadera”, [en] J. Mangas - M. A. Novillo (eds.), El territorio de las ciudades romanas, Madrid, 385-424.

(2014): "Hércules en la Meseta. Testimonios, carácter y conexiones", [en] J. Mangas - M. A. Novillo (eds.), Santuarios suburbanos y del territorio en las ciudades romanas, Madrid, 383-411.

Hurtado Aguña, J.

(1999): "Las villas carpetanas en el contexto de la economía bajoimperial", Studia Historica. Historia Antigua 17, 395-409.

(2005): Los territorios septentrionales del Conventus Carthaginesis durante el Imperio Romano, BAR n ${ }^{\circ} 1415$, Oxford.

JimÉnez GuiJArRo, A. (2006): "El Beneficio: una ya vieja alternativa para Miaccum, Nuevo Miliario 3, 49-56.

JuAn Tovar, L. C. (1990): “Alfares y vías de comunicación en la Hispania romana. Acercamiento a una relación”, [en] AA.VV., Simposio sobre la red viaria en la Hispania romana, Zaragoza, 293-299.

LóPEz BARJA DE Quiroga, P. (2008): "La concepción política del territorio en la Roma republicana", [en] J. Mangas - M. A. Novillo (eds.), El territorio de las ciudades romanas, Madrid, 9-30.

MacíAs, F. (2008): “Vici y articulación del territorium: Segobriga, Ercavica y Valeria”, [en] J. Mangas - M. A. Novillo (eds.), El territorio de las ciudades romanas, Madrid, 617-632.

MANGAS, J.

(1998): "Nueva inscripción romana (Monasterio de El Paular, Madrid)", Anales del Instituto de Estudios Madrileños 25, 211-213.

(2008a): "Límites exteriores e interiores del territorio de las civitates astures", [en] J. Mangas - M. A. Novillo (eds.), El territorio de las ciudades romanas, Madrid, 83-106.

(2012); "Integración de galaicos, astures y cántabros en el sistema romano de administración local", [en] M. Cassa et alii (eds.), Pinora amicitiae. Scritti di storia antica e storiofrafia offerti a Mario Mazza, III, Roma, 53-69.

(2013): "Ciudades sin urbe en la Hispania romana", [en] A. Martínez et alii, ÁGALMA. Ofrenda desde la Filología Clásica a Manuel García Teijeiro, Valladolid, 801-824.

(2014): "La romanización de Carpetania durante la República romana", [en] I Simposio sobre los Carpetanos: Arqueología e Historia de un pueblo de la Edad del Hierro (12-14, marzo, 2013), Alcalá de Henares, 407-425.

Mangas, J. - Novillo, M. A. (eds.)

(2008): El territorio de las ciudades romanas, Madrid.

(2014): Santuarios suburbanos y del territorio en las ciudades romanas, Madrid.

Mangas, J. - Álvarez, A. - Benítez, R. (2013-2014): “Casa / casae en el Occidente romano", Hispania Antiqua 37-38, 271-298. 
Mangas, J. - Carrobles, J. - Rodríguez, S. (1992): “Deana y mulieres. Nueva inscripción de la provincia de Toledo", Gerión 10, 243-258.

Mangas, J. - Novillo, M. A. (2014): “Ars picaria. La pez (pix) en la Hispania romana”, [en] Actas. CXVIIICIA: centro y periferia en el Mundo Clásico, Mérida, 187-191.

MARINÉ, Ma (1990): "Fuentes y no fuentes de las vías romanas: los ejemplos de la Fuenfría (Madrid) y los del Puerto del Pico (Ávila)", [en] AA.VV., Simposio sobre la red viaria en la Hispania romana, Zaragoza, 325-340.

Martínez, A. - Ortega, B. - Velasco, H. - Zamora, H. (2014): ÁGALMA. Ofrenda desde la Filología Clásica a Manuel García Teijeiro, Valladolid.

Montero, I. - Alcolea, J. - Álvarez y Baena, J. - García, M. A. - Gómez, J. - Ramos, M. L. (2007): Poblamiento prerromano en la Dehesa de la Oliva (Patones, Madrid)" [en] A. F. Dávila (ed.), Estudios sobre la Edad del Hierro en la Carpetania. Registro arqueológico, secuencia y territorio. Zona arqueológica, 10, vol. II, Madrid, 120-130.

Montero, S. (2014): “El encuentro en el río: religión y diplomacia en Roma”, [en] R. M ${ }^{\mathrm{a}}$ Cid López - E. García Fernández (eds.), Debita verba. Estudios en Homenaje al profesor Julio Mangas, vol. II, Oviedo, 447-462.

Montero Vítores, J. (1991): Carpetanos y vettones en la Geografia de Ptolomeo, Madrid (Tesis. U.C.M.).

Morales Segura, M. - Segura Graiño, C. (2014): “Termas, baños y balnearios en la ordenación social del territorio", [en] R. Cid - E. García Fernández (eds.), Debita verba. Estudios en Homenaje al profesor Julio Mangas, vol. II, Oviedo, 309-322.

Morín de Pablos, J. - Urbina, D. - López Fraile, F. J. - Escolá, M. - Pérez-Juez, A. - Agustí, E. - Barroso, R. (2009): "El Cerro de La Gavia (Villa de Vallecas, Madrid capital). El urbanismo de un poblado de la Segunda Edad del Hierro en la Comunidad de Madrid", [en] Actas. III Jornadas de Patrimonio Arqueológico en la Comunidad de Madrid, Madrid, 233-251.

Moya-Maleno, P.R. (2008): “Ager y afiladeras: dos hitos en el estudio del municipio laminitano (Alhambra, Ciudad Real)", [en] J. Mangas - M. A. Novillo (eds.), Santuarios suburbanos y del territorio en las ciudades romanas, Madrid, 557-588.

Muñoz CARballo, G.

(1974): "Excavaciones en el castro de la Dehesa de la Oliva", Boletín de la Asociación Española de Amigos de la Arqueología 2, 46-48.

(1980): “Castro de la Dehesa de la Oliva. II”, [en] II Jornadas de Estudios sobre la provincia de Madrid, Madrid, 57-62.

(1994): "Excavaciones en el castro de la Dehesa de la Oliva (Patones, Madrid)", Boletín de la Asociación Española de Amigos de la Arqueología 34, 39-52.

Orejas, A. - Fernando, A. (2014): “Metalla, civitates y loca sacra (Maragatería, Teleno y Alto Bierzo)", [en] J. Mangas - M. A. Novillo (eds.), Santuarios suburbanos y del territorio en las ciudades romanas, Madrid, 277-294.

Puche, O. - AyarzagüEnA, E. (eds.) (2005): Minería y metalurgia históricas en el Sudoeste europeo, Madrid.

Quero, S. - Pérez, A. - Morín, J. - Urbina, D. (coords.) (2005): El Cerro de la Gavia. El Madrid que encontraron los romanos, Madrid.

Rabanal, M. A. - García Martínez, S. Ma (2001): Epigrafía romana de la provincia de León, León. 
Rodríguez Gutiérrez, O. (2011): Hispania arqueológica. Panorama de la cultura material de las provincias hispanorromanas, Sevilla.

RoldÁn, J. M. (1975): Itineraria Hispana, Valladolid y Granada.

Rubio, R. (2010): “El circo romano de Toledo y la Vega Baja en época romana”, [en] M. A. Valero (coord.), La Vega Baja. Investigación, documentación, hallazgos, Toledo, 34-54.

Rubio, R. - VAlero, M. A. - Molina, M. - Arcos, Ma C. (2010): "La villa romana de la Fábrica de Armas (Toledo)", [en] M. A. Valero (coord.), La Vega Baja. Investigación, documentación, hallazgos, Toledo, 58-82.

Ruiz Trapero, Ma (2001): Inscripciones latinas de la Comunidad Autónoma de Madrid (s. I-VIII), Madrid.

Sánchez Montes, A. L. - Rascón Marqués, S. (2006): “La Villa del Val y la necrópolis del Camino de los Afligidos (Alcalá de Henares)", Zona Arqueológica 8, 293-308.

SAncho Rocher, L. (1981): El Convento Jurídico Caesaraugustano, Zaragoza.

SAnz PÉrez, V. (2010): La romanización jurídica de la Meseta Superior de la Península Ibérica. Su alcance e intensidad y la legislación flavia, Segovia.

Scherillo, G. (1945): Lezioni di diritto romano. Le cose, Milano.

Schulten, A. (1937): Fontes Hispaniae Antiquae, IV, Barcelona.

Solana, J. Ma (2014): “Construcción y reparación de vías y puentes en la Hispania romana: los términos refecit y perfecit recogidos en los miliarios", [en] R. M ${ }^{\mathrm{a}}$ Cid - E. García Fernández (eds.), Debita verba. Estudios en Homenaje al profesor Julio Mangas, vol. II, Oviedo, 335-363.

Solana, J. M ${ }^{\text {a }}$ - Hernández Guerra, L. (2002), La política viaria en Hispania. Siglo IV d. C., Valladolid.

Solana, J. M ${ }^{\mathrm{a}}$ - SAgredo, L. (2006): La red viaria romana en Hispania. Siglos I-IV d.C., Valladolid.

StYlow, A.

(1990): "Neue Inschriften aus Carpetanien (Hispania Citerior)", Chiron 20, 307-344. (1994): "Maximino y Máximo en Hispania", [en] AA.VV., Historiam pictura refert. Miscellanea in onore di Padre Alejandro Recio Veganzones, Ciudad del Vaticano, 575-590.

UrbinA, D. (1999): "Introducción al poblamiento romano en el valle bajo del río Alberche. Toledo", Studia Historica. Historia Antigua 17, 371-394.

VAlero, M. A. (coord.) (2010): La Vega Baja. Investigación, documentación, hallazgos, Toledo.

Valero, M. A. - Arcos, Ma C. - Molina, M. (2010): "Intervenciones arqueológicas en la Vega Baja de Toledo: historia de un yacimiento", [en] M. A. Valero (coord.), La Vega Baja. Investigación, documentación, hallazgos, Toledo, 12-31.

VAliente CÁnovas, S. - AyarzagüEna, M. (2005): "Las cerámicas a mano utilizadas en la producción de sal en las salinas Espartinas (Ciempozuelos, Madrid)", [en] O. Puche - E. Ayarzagüena (eds.), Minería y metalurgia históricas en el Sudoeste europeo, Madrid, 6170.

Valiente Cánovas, S. - Ayarzagüena, M. - Moncó, C. - Carvajal, D. (2002): "Excavación arqueológica en las salinas Espartinas (Ciempozuelos) y prospecciones en su entorno", Archaia 2, 33-45. 
VelazA, J. (2008): “La onomástica personal en la epigrafía romana de la Meseta Meridional: una aproximación", [en] G. Carrasco (coord.), La romanización en el territorio de CastillaLa Mancha, Cuenca, 367-383.

Vigil EscalerA, A. (2012): "El asentamiento encastillado altomedieval de la Dehesa de la Oliva (Patones, Madrid)", [en] J. A. Quirós - J. M. Tejado Sebastián (coords.), Los castillos altomedievales en el noroeste de la Península Ibérica. Studia Historica. Historia Medieval, 239-262.

Wiegels, R. (1985): Die Tribusinschriften des römischen Hispanien. Ein Katalog, Berlin.

Zarzalejos, M. (2002): El alfar romano de Villamanta (Madrid), Madrid. 